\title{
The Role of Depression in Coronary Artery Disease
}

\author{
André Luiz Langer Manica, Carolina Garcia Soares Leães, Benício Noronha Frey, \\ Mário Francisco Juruena
}

\author{
Porto Alegre, RS - Brazil
}

\section{General considerations}

The concept of depression encompasses a series of psychopathological disorders that differ in regard to symptomatology, severity, course and prognosis. It is important to individualize these disorders for a better understanding of the following studies and of their diagnostic management.

Major depressive disorder, as defined by CID X ${ }^{1}$ and DSM IV $^{2}$, may have different clinical characteristics (table I). A specifier that may be employed in diagnosing the major depressive episode is the presence of melancholic symptoms (melancholia), whose main characteristic is the loss of interest and pleasure in all or almost all activities and a lack of reactivity to usually pleasant stimuli. In these circumstances, the depressive mood does not improve, not even temporarily, when something positive happens. Yet, at least three of the following symptoms should be present for the diagnosis of major depression to be made: depressive mood qualitatively different from the normal, worsening in the morning, terminal insomnia (to wake up at least two hours before the usual time), psychomotor retardation or agitation, anorexia or significant weight loss (5\% of the body weight per month), excessive or inappropriate guilt. Sometimes, however, the depressive disorder is atypical with mood reactivity, i.e., enhancement of the mood in response to real or potential positive events, significant weight gain, increase in appetite, hypersomnia, sensation of heaviness in the upper and lower limbs, in addition to a prolonged pattern of sensitivity to interpersonal rejection resulting in significant social or occupational impairment ${ }^{1,2}$.

The dysthymic disorder (dysthymia) is characterized by a chronically depressed mood lasting for most of the day, for the majority of days, and lasting for at least two years ${ }^{1,2}$. The individual may note significant reduction in usual interests and in self-criticism, frequently seeing himself or herself as uninteresting and incapable. As these symptoms become part of daily life, usually they are not mentioned by the patient unless directly inquired about by

Fundação Faculdade Federal de Ciências Médicas de Porto Alegre - Porto Alegre, RS Mailing Address: Mário Francisco Juruena - Rua Prof. Annes Dias, 154/906 90020-090 - Porto Alegre, RS, Brazil the physician ${ }^{2}$. Minor depression is characterized by depressive episodes of at least two weeks that do not fulfill the 5 criteria required for major depression ${ }^{2}$. An adjustment disorder with depressive mood, however, is directly associated with identifiable psychosocial stressing factors and occurs within three months of the onset of the stressors and persists for up to 6 months after the end of the stressing factors, not fulfilling the criteria for major depression ${ }^{2}$. On the other hand, secondary depression is a direct physiological consequence of a general medical condition or may result from the abuse (or withdrawal) of any substance ${ }^{2}$.

Studies point to a prevalence of $13 \%$ and $5 \%$ for major depression and dysthymia, respectively ${ }^{3}$, and of $23 \%$ for minor depressive symptoms ${ }^{4}$ in the general population. Recent studies show that depression and anxiety play a preponderant role in the genesis and course of cardiovascular diseases (fig. 1). Severe depressive symptoms have been associated with an increase in the risk of the development of acute myocardial infarction (AMI) ${ }^{5,6}$, as well as in early post-AMI mortality ${ }^{5-8}$. The role of stress, excessive preoccupations and aggressive behavior in the development of cardiovascular diseases has also been investigated ${ }^{5,9}$.

The present study aims to address the main features of the association of depression-coronary artery disease (CAD), considering the great prevalence of these two entities in the overall population and their significant impact on patients' quality of life.

\section{Depression. Risk factor for the development of ischemic heart disease}

In a follow-up study of patients with no history of cardiac disease, an increased fatal or nonfatal risk for $\mathrm{CAD}$ was demonstrated in the patients with depressive symptoms ${ }^{10}$. Another study also verified a risk of the development of AMI two times higher in patients with episodes of dysphoria (at least two weeks of deep sadness) and four times higher in those patients with major depression, as compared with individuals with no antecedents of depression ${ }^{11}$. In addition, it has been demonstrated that depression is an independent risk factor for the development of ischemic heart disease, even when the risk factors considered traditional (smoking, hypertension, hyperlipidemia, sex, age, obesity, sedentary lifestyle) are controlled ${ }^{5,6,12,13}$. 


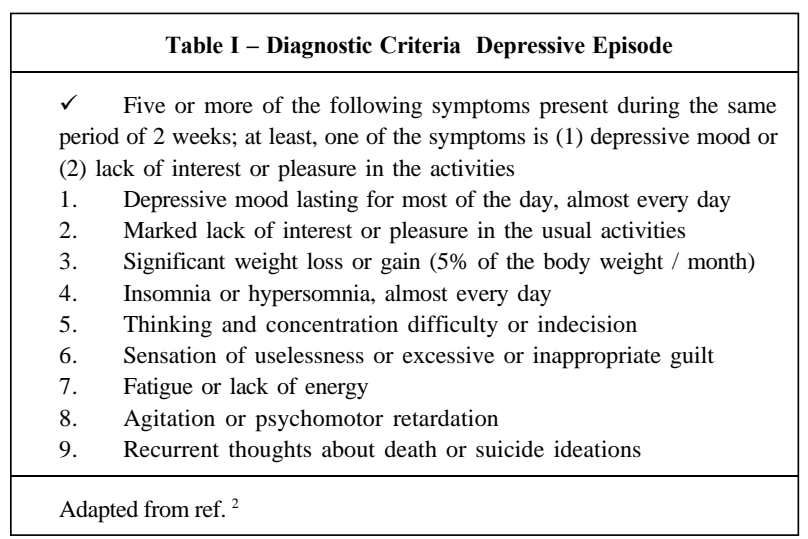

\section{Post-AMI depression. Epidemiology (table II) and prognostic factors}

Depressive syndrome has been commonly found in patients in the post-AMI period, reaching a prevalence of $45 \%{ }^{14,15}$. Among the patients who developed depressive symptoms, $15 \%$ to $33 \%$ fulfilled the criteria for major depression ${ }^{14,16}$. This finding persisted after a 3-month followup, in which $33 \%$ to $44 \%$ of the patients still fulfilled these criteria ${ }^{14,15}$. Another study carried out with patients in the
post-AMI period showed a prevalence of $18 \%$ to $27 \%$ for major and minor depression, respectively (according to the Research Diagnostic Criteria). From these patients, 77\% and $36 \%$ still had depressive symptoms after 3 months ${ }^{14}$. In addition, it was also observed that $17 \%$ to $18 \%$ of the patients with coronary artery disease angiographically diagnosed, with no history of AMI, have findings of major depression ${ }^{17-19}$ and $17 \%$ of minor depression ${ }^{19}$. It is described in the literature that patients with associated comorbidities, negative experiences during life and familial history of psychopathologies comprise a risk group for the development of post-AMI depression ${ }^{15}$ (table II). However, severity of the cardiac disease does not seem to be directly related to an increased risk of post-AMI depression ${ }^{14}$. Other psychosocial factors that also seem to influence the postAMI depression are stress, social isolation ${ }^{17}$, and low educational level ${ }^{20,21}$ (table III).

Studies have shown that depression is also an important prognostic factor in post-AMI patients relating to a significant increase in CAD morbidity and mortality ${ }^{7-9,22,23}$. Depression may double the risk for fatal outcomes in individuals in the age range of 40-60 years with cardiovascular diseases ${ }^{6}$. Reports in the literature show that major depression ${ }^{7,8}$ and depressive symptoms ${ }^{8}$ have an important impact on the prognosis of hospitalized patients in the post-AMI period during the first 6 to 18 months ${ }^{7,8,24}$. This higher risk of

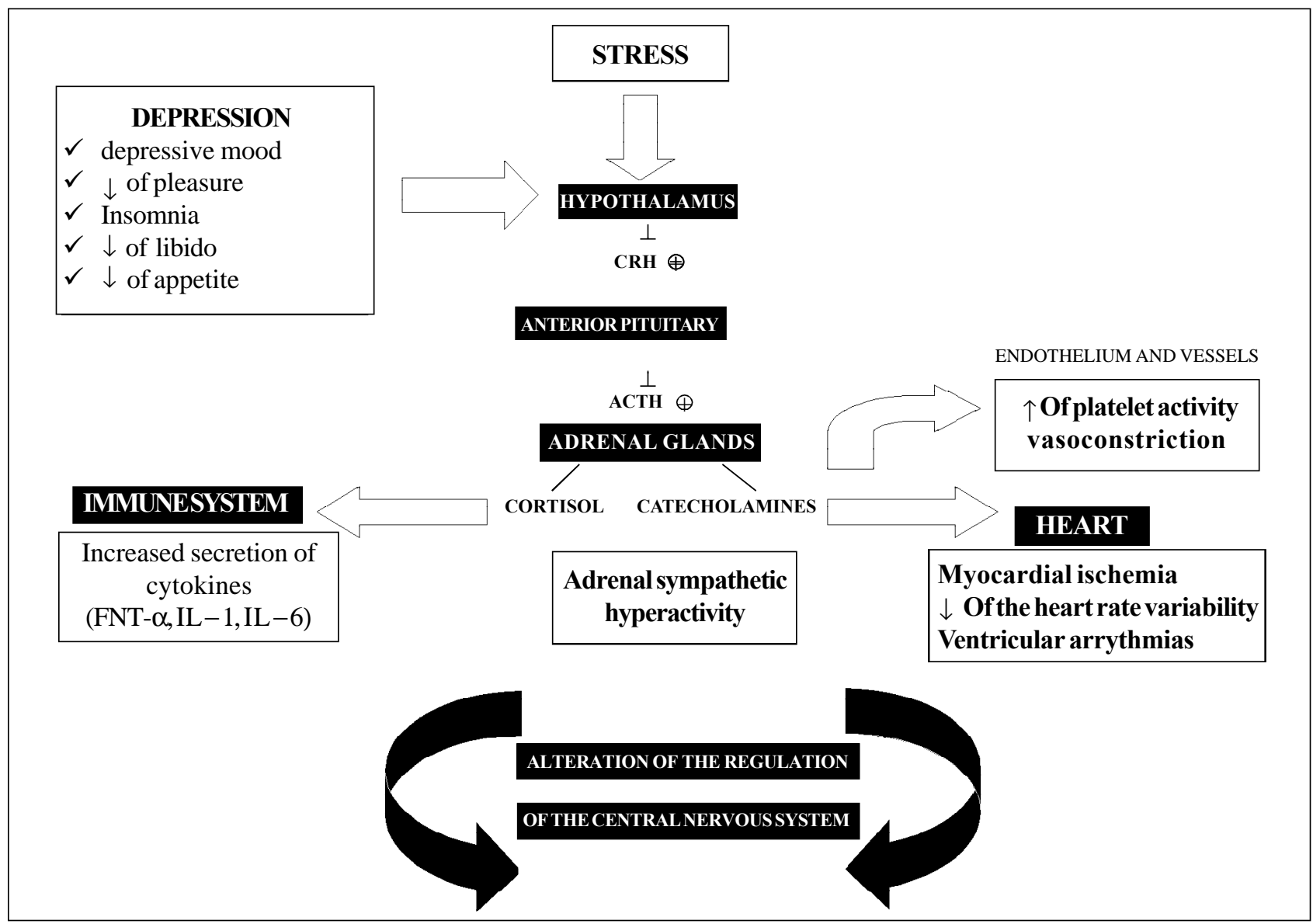

Fig. 1 - Relation between major depression and cardiovascular disease 
Table III - Predisposing factors for Post-AMI depression

$\checkmark$ Associated comorbidities

$\checkmark$ Negative experiences in life

$\checkmark$ Prevalence of post-AMI minor depression: 27\%

$\checkmark$ Familial history of psychopathologies

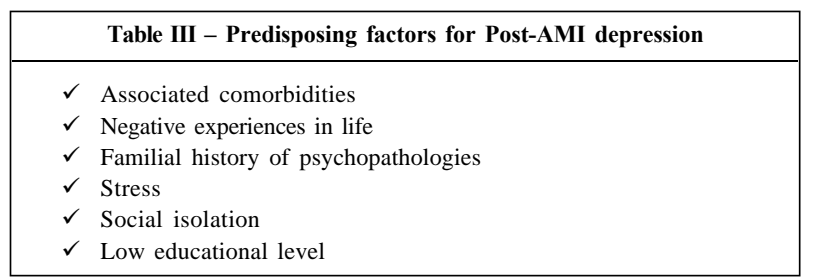

death seems to be equivalent to or even higher than that of the already known risk factors for mortality in ischemic heart disease. Studies have shown that an intense depressive symptomatology in the post-AMI period is a very good predictor of mortality ${ }^{7,8,15,25}$, even after exclusion of other prognostic factors (left ventricular dysfunction and previous AMI) ${ }^{7,8}$. Recent studies suggest that depressive symptoms may influence the functionality of CAD more than the number of impaired arteries ${ }^{26}$.

Major depression and the depressive symptoms exert a negative impact, not only on the physical recovery of the patients but also on their functionality. In a follow-up study of patients with CAD, $38 \%$ of those who had fulfilled the criteria for major depression returned to work in 3 months, compared with $63 \%$ of the patients who had not had previous depression ${ }^{14}$.

The association of depressive symptoms and CAD seems to be different between the sexes. Two studies have shown a higher prevalence of depression among women with or without $\mathrm{CAD}^{14,25}$. An increased trend toward postAMI mortality in the female sex has also been observed ${ }^{27}$. This fact may be related to the occurrence of more severe depression in women with ischemic heart disease ${ }^{28}$.

Considering the high prevalence of depression among patients with heart disease, as well as its prognostic impact on $\mathrm{CAD}$, it is important to appraise the depressive symptoms in these cases, because the fact of not recognizing these disturbances implies an even worse prognosis for these patients. It is worth stressing that some patients may have atypical depressive symptoms, either predominating symptoms such as excessive fatigue and pain, or with complaints such as hypersomnia, hyperphagia, weight gain, and restlessness. Another finding that may help in recognizing and diagnosing depressive disorders is the anxiety component. A study indicates that two thirds of the patients with depression have symptoms of anxiety and that this association leads to an increase in the severity and chronicity of the disease, in addition to a decrease in the therapeutical response ${ }^{29}$.

\section{Depression and ischemic heart disease. Mechanisms of association}

Two types of mechanisms may explain the relation between depression and cardiovascular disease: the psychosocial or behavioral and the physiopathological mechanisms. The latter involve increase in platelet aggregation, reduction in the heart rate (HR) variability, and alterations in the regulation of the autonomic nervous system and of the hypothalamic-pituitary-adrenal (HPA) axis.

\section{A. Psychosocial mechanisms}

Depressed patients tend to adhere less to medicamentous treatment, to programmed exercises ${ }^{30}$, to smoking cessation $^{31}$, and to dietary changes ${ }^{6,7,11}$. Some studies have also shown a greater prevalence of women and unmarried individuals in the depressed group ${ }^{6,31,32}$, in addition to a greater abuse of and dependence on alcohol ${ }^{11}$ and tobacco ${ }^{6}$. These factors may significantly contribute to the increase in cardiovascular morbidity and mortality in patients with depressive symptoms.

\section{B. Pathophysiological mechanisms}

At least 4 possible factors may be related to the pathophysiological mechanisms: increase in the platelet activity, alteration in the regulation of the autonomic nervous system, decrease in the HR variability, and dysfunction of the HPA axis.

\section{Increase in platelet activity}

A recent study using flow cytometry showed an increase in platelet activity in depressed patients as compared with healthy individuals. In this study, an increase in the basal platelet activity of $41 \%$ in the depressed group was observed. In addition, an increment of $24 \%$ in the binding of a specific substance to sites of the platelet glycoprotein IIIa induced by proclotting endogenous ligands, such as fibrinogen (MoAb anti-LIBS1), after changing from dorsal decubitus to the orthostatic position, was also observed ${ }^{32}$. Another study also observed a higher platelet activation in patients with CAD and major depression as compared with healthy individuals and nondepressed individuals with $\mathrm{CAD}$, through the increase in the plasma levels of products secreted by platelets ${ }^{33}$. The mechanism by which this hyperactivity occurs remains unknown. One hypothesis is related to serotonin (5-HT). Platelet serotonergic stimulus is known to induce platelet aggregation and coronary arterial vasoconstriction through $5-\mathrm{HT}_{2}$ receptors. This vasoconstriction occurs preferentially when a disorder exists in the regulatory endothelial mechanisms, as occurs in $\mathrm{CAD}^{33-35}$. Even though serotonin, when isolated, is a weak plateletaggregating agent, it promotes amplification of platelet reactivity to several substances, such as thromboxane A2, catecholamines and thrombin. In addition, through the $5-\mathrm{HT}_{2}$ receptors, serotonin increases the area of platelet aggregation and the release of metabolites of arachidonic acid in response to low levels of other platelet agonists ${ }^{35}$.

The fact that depressed patients have an increase in the density of platelet 5- $\mathrm{HT}_{2}$ receptors ${ }^{36-40}$ and a decrease in the 
density of platelet and cerebral serotonin transporters ${ }^{41-46}$ has also been described in the literature. Therefore, this causes a greater susceptibility of the depressed patients to platelet activation and to coronary arterial vasoconstriction by serotonergic stimulus through the prolonged exposure of this higher number of receptors to serotonin action.

\section{Sympathetic hyperactivity}

Several clinical and experimental studies point out that in patients with preexistent $C A D$ ventricular fibrillation is the most common cause of sudden death, which occurs when an electrical stimulus reaches the myocardium during the repolarization period and surpasses the excitability threshold, triggering an electrical myocardial instability. This threshold is decreased in cardiomyopathies, especially in myocardial ischemia ${ }^{47}$. Another factor related to reduction in the excitability threshold, in human and animal models, is the stimulus of the sympathetic nervous system ${ }^{48,49}$.

Among patients with CAD, those with major depression have a higher prevalence of ventricular tachycardia as compared with nondepressed patients ${ }^{50,51}$. One study ${ }^{52}$ showed a mortality rate five times higher in patients undergoing treatment for supraventricular and ventricular tachyarrhythmias, who had depressive symptoms at the moment of the diagnosis as compared with those who did not have the symptoms ${ }^{52}$. Increase in the plasma levels of norepinephrine in patients with major depression ${ }^{53-55}$ and bipolar affective disorder (depression and mania) ${ }^{53}$, as well as high urinary levels of norepinephrine metabolites ${ }^{54,55}$ were also observed when compared with the levels in healthy individuals. Other studies have shown that the presence of melancholic symptoms increases even more the plasma levels of norepinephrine as compared with levels in patients with dys thymia and major depression without history of melancholia ${ }^{56,57}$. In addition, an 8-times higher mortality rate due to heart disease was found in patients with episodes of melancholia as compared with the general population ${ }^{57}$.

This sympathetic hyperactivity of the HPA axis may correspond to the main mechanism through which depression is associated with an increase in sudden death due to ventricular tachycardia in patients with CAD.

\section{Decrease in the heart rate variability}

Recent studies have reported that patients with depression have a reduction in the HR variability due to an increase in the autonomic tonus ${ }^{58,59}$. This type of alteration of the $\mathrm{HR}$ is an independent risk factor for mortality in post-AMI patients ${ }^{60,61}$. A decrease in the vagal tonus reduces the $H R$ variability and predisposes a patient, therefore, to the development of ventricular fibrillation, findings that were confirmed in animal studies with AMI experimentally induced ${ }^{47,62}$.

\section{Dysfunction of the hypothalamic-pituitary- adrenal (HPA) axis}

It is long established and well known that excessive plasma levels of corticosteroids cause hypertriglyceridemia, hypercholesterolemia, and hypertension. A series of studies reports that alterations in the HPA axis of depressed patients cause high plasma levels of cortisol ${ }^{63-66}$. The stress status caused by depression may lead to a hyperactivity of the HPA axis due to an increase in the secretion of the corticotropin releasing hormone $(\mathrm{CRH})$ by the hypothalamus ${ }^{65,66}$ and a hyperresponsiveness of the adrenal cortex to adrenocorticotropic hormone $(\mathrm{ACTH})^{67,68}$. Nonsuppression of the cortisol secretion after administration of exogenous dexamethasone in depressed patients was observed for the first time by Carrol et al in $1968^{69}$. The dexamethasone suppression test (DST) is more often altered in melancholic patients $(>50 \%)$ than in patients with minor depression $(23 \%)$ or with adjustment reactions $(10 \%)^{70,71}$. Depressed patients without suppression on the DST have serum levels of noradrenaline significantly higher than depressed patients with suppression on the $\operatorname{DST}^{72}$.

\section{Depression and CAD. Therapeutical mana- gement}

The strong evidence that patients with depressive symptoms more often develop symptomatic and fatal ischemic cardiac events generates the following basic questions: Will the treatment of depression alter these superior indices of mortality and morbidity in depressed patients with CAD? Which is the best antidepressant for the treatment of these patients?

\section{A. Psychosocial treatment}

Psychosocial interventions have proved efficient for the emotional improvement of patients and for the reduction in post-AMI mortality. Studies have shown that psychological support in coronary units ${ }^{73}$ and stress management programs ${ }^{74,75}$ for post-AMI patients have reduced the depressive and anginal symptoms of these patients. The symptomatic reduction obtained through a psychosocial approach may significantly contribute to the clinical and psychological improvement of these patients.

\section{B. Pharmacological treatment}

Tricyclic antidepressants (TAD) have proved to be cardiotoxic, and their most common noxious cardiovascular effect is orthostatic hypotension ${ }^{76,77}$ (table IV). In two previous studies, this noxious effect caused interruption of the antidepressant treatment in approximately $10 \%$ of the patients without heart disease ${ }^{78}$ and in $25 \%$ to $50 \%$ of the patients with preexistent heart disease ${ }^{79}$. This orthostatic hypotension caused by TAD is more marked in patients with disorders of heart conduction, mainly bundle-branch block, and in patients with heart failure ${ }^{80}$. Other studies report a strong association between the use of TAD and hip fractures ${ }^{81}$ and a $4 \%$ increase in the incidence of lacerations and fractures in patients treated with imipramine ${ }^{82}$. In 


\begin{tabular}{|cc|}
\hline \multicolumn{2}{|c|}{ Table IV - Cardiovascular effects of the antidepressants } \\
\hline Tricyclic antidepressants & $\begin{array}{c}\text { Selective serotonin } \\
\text { reuptake inhibitors }\end{array}$ \\
\hline$\checkmark$ Orthostatic hypotension & $\checkmark$ Do not cause orthostatic hypotension \\
$\checkmark$ Retardation of the & $\checkmark$ Do not interfere with \\
electric conduction & electric conduction \\
$\checkmark$ Quinidine- & $\checkmark$ Do not have quinidine \\
like action & like action \\
$\checkmark$ Do not affect left & $\checkmark$ Relatively safe \\
ventricular function & even in overdose \\
\hline
\end{tabular}

addition, orthostatic hypotension may be a precipitant factor for AMI and stroke ${ }^{83}$.

Recent studies have shown that TADs have an antiarrhythmic effect similar to that of the class IA agents (calcium channel blockers), such as quinidine (table IV). Therefore, TADs may cause an extension of the QT, PR and QRS intervals in patients with myocardial lesions and an arrhythmogenic effect or exacerbation of the degree of the bundle-branch block in patients with disorders of heart conduction ${ }^{26}$. The results of the Cardiac Arrhythmia Suppression Trials I and II (CAST I and II) showed that patients after an AMI, prophylactically treated with certain types of antiarrhythmic agents, including class IA agents, showed a morbidity and mortality rate higher than those treated with placebo ${ }^{84,85}$. Considering this, we may attribute these effects to the TADs, because they also act through that mechanism. It is generally agreed that the use of TADs in the first 2 or 3 months after an AMI should be avoided whenever possible because, during this recovery period, patients are more sensitive to the noxious cardiovascular effects of these drugs ${ }^{76,77}$.

Due to the lowest potential of noxious cardiovascular effects and to the highest safety of their use even in overdoses, the selective serotonin reuptake inhibitors (SSRIs) may show advantages in the therapeutical management of patients with CAD and depression. Among the drugs of this class are fluoxetine, paroxetine, sertraline, fluvoxamine, and citalopram. Incidence of noxious cardiovascular effects of SSRI is around $0.0003 \%$, ranging from electrocardiographic alterations to arrhythmias, thrombophlebitis and stroke ${ }^{86}$. It is known that this class of drugs does not cause an extension of the PR, QT and QRS intervals and they do not block the calcium channels ${ }^{87,88}$, unlike the TADs (table V). Despite being a relatively safe class of drugs, the SSRIs have a great potential for medicamentous interaction through liver metabolism of cytochrome P450, and they may increase the plasma levels of drugs also metabolized through this via, such as the antiarrhythmic agents, TADs and phenothiazines ${ }^{89,90}$. This could increase the potential cardiotoxicity of these drugs. In addition, SSRIs may interfere with the cardiovascular integrity through amplification of the platelet aggregation and vasoconstriction in response to serotonergic stimuli, due to an increase in the serotonin concentration in platelet and cerebral sites ${ }^{91,92}$.
It is also necessary to consider the risk:benefit ratio of the use of antidepressant drugs in the treatment of patients with CAD and associated depression. For example, studies have shown that SSRIs have antidepressant efficacy similar to that of the TADs in patients under 65 years of age with moderate to severe depression ${ }^{93-95}$, but little is known about the efficacy of the SSRIs in the elderly and patients with heart disease. On the other hand, TADs have been widely studied and have proved to be greatly effective in the treatment of depression in the elderly. A study in depressed older patients treated with nortriptyline (TAD) or fluoxetine (SSRI) showed a superior index of response in the first group (67\% versus $23 \%$ ), and this index was even higher in the patients who had melancholia ( $83 \%$ versus $10 \%)^{96}$. Another recent double-blind multicenter randomized study compared the efficacy of nortriptyline (TAD) with that of paroxetine (SSRI) in depressed patients with $\mathrm{CAD}^{97}$. Both antidepressants showed similar efficacy in the treatment of depression but the patients treated with nortriptyline showed a significantly higher rate of cardiac side effects, such as increase in the heart rate and reduction in the heart rate variability.

Atypical antidepressant agents (with mechanisms of action different from those of the TADs and SSRIs), such as bupropion, venlafaxine, mirtazapine, nefazodone, trazodone, and tianeptine, still lack controlled studies for a better assessment in regard to the safety of use of these drugs in patients with heart disease. Bupropion does not have major effects on myocardial conduction or contractility, but may cause light orthostatic hypotension and increase in blood pressure (BP) ${ }^{26,98}$. Venlafaxine has been associated with an increase in BP and HR, in addition to hypertriglyceridemia ${ }^{99,100}$. Mirtazapine seems to be a relatively safe drug because the indices of hypertension, orthostatic hypotension and tachycardia reported were similar to those of the placebo group ${ }^{101}$. Until the present moment, there are no reports on cardiac alterations with the use of nefazodone; we stress, however, the need for controlled studies. Trazodone, on the other hand, does not seem to have effects on the cardiac conduction when used in therapeutical doses or even toxic doses; however, there are reports of cases of nonsustained ventricular tachycardia ${ }^{102}$ and orthostatic hypotension ${ }^{103}$ with the use of this drug. Tianeptine seems to be a relatively safe drug ${ }^{104}$, even though there is no study of depressed patients with underlying heart disease.

Evidence exists that the antidepressant treatment in patients with depression and CAD has a significant prognostic impact on the evolution of heart disease ${ }^{18,105}$. A study reports a higher recurrence of AMI in depressed patients with CAD, who undergo inadequate antidepressant treatment, as compared with those who undergo correct treatment ${ }^{105}$. However, further studies regarding the risk: benefit ratio of the use of the diverse classes of antidepressants in patients with CAD are required for the adoption of standardized therapeutical management of these patients. 


\section{References}

1. Classificação de Transtornos Mentais e de Comportamento da CID-10. Diretrizes Diagnósticas e de Tratamento para Transtornos Mentais em Cuidados Primários. Organização Mundial de Saúde. Porto Alegre: Artes Médicas, 1998: 34.

2. DSM-IV. Diagnostic and Statistical Manual of Mental Disorders. $4^{\text {th }}$ ed. :, 1994.

3. Kessler RC, McGonagle KA, Zhao S, et al. Lifetime and 12-months prevalence of DSM III-R psychiatric disorders in the United States: Results from the National Comorbidity Survey. Arch Gen Psychiatry. 1994; 51: 8-19.

4. Johnson J, Weissman MM, Klerman GL. Service utilization and social morbidity associated with depressive symptoms in the community. JAMA 1992; 267: 1478-83.

5. Barefoot JC, Schroll M. Symptoms of depression, acute mycardial infarction, and total mortality in a community sample. Circulation 1996; 93 : 1976-80.

6. Aromaa A, Raitasalo R, Reunanen A, et al. Depression and cardiovascular diseases. Acta Psychiatr Scand 1994; 377: 77-82.

7. Frasure-Smith N, Lespérance F, Talajic M. Depression following myocardial infarction: impact on 6-month survival. JAMA 1993; 270: 1819-24.

8. Frasure-Smith N, Lespérance F, Talajic M. Depression and 18-month prognosis after myocardial infarction. Circulation 1995; 91: 999-1005.

9. Ahern DK, Gorkin L, Anderson JL, et al. Biobehavioural variables and mortality or cardiac arrest in the cardiac arrhythmia pilot study (CAPS). Am J Cardiol 1990; 66: 59-62

10. Anda R, Williamson D, Jones D, et al. Depressed affect, hopelessness, and the risk of isquemic heart disease in a cohort of us adults. Epidemiology 1993; 4: 285-99.

11. Pratt LA, Ford DE, Crum RM, et al. Depression, psychotropic medication and risk of myocardial infarction: prospective data from the Baltimore ECA follow up. Circulation 1996; 94: 3123-9

12. Ford DE, Mead LA, Chang PP, et al. Depression predicts cardiovascular disease in men: the precursors study. Circulation 1994; 90(suppl I): 614.

13. Hippisley-Cox J, Fielding K, Pringle M. Depression as risk factor for ischaemic heart disease in men: population based case-control study. Br Med J 1998; 316: 1714-9.

14. Schleifer SJ, Macari-Hinson MM, Coyle DA, et al. The nature and course of depression following myocardial infarction. Arch Intern Med 1989; 149: 1785-9.

15. Garrity TF, Klein RF. Emotional response and clinical severity as early determinants of 6-months mortality after myocardial infarction. Heart Lung 1975; 4: 730-7.

16. Carney RM, Freedland KE, Jaffe AS. Insomnia and depression prior to myocardial infarction. Psychosom Med 1990; 52: 603-9.

17. Carney RM, Rich MW, teVelde A, Saini J, Clark K, Jaffe AS. Major depressive disorder in coronary artery disease. Am J Cardiol 1987; 60: 1273-5.

18. Carney RM, Rich MW, Freedland KE, et al. Major depressive disorder predicts cardiac events in patients with coronary artery disease. Psychosom Med 1988; 50: 627-33.

19. Hance M, Carney RM, Freedland KE, Skala J. Depression in patients with coronary heart disease: a 12-month follow-up. Gen Hosp Psychiatry 1996; 18: 61-5.

20. Case RB, Moss AJ, Case N, Mcdermott M, Eberly S. Living alone after myocardial infarction: impact on prognosis. JAMA 1992; 267: 515-9.

21. Masthews KA. Are sociodemographic varables markers for psychological determinants of health? Health Psychol 1989; 8: 641-8.

22. Falgar P, Appels A. Psychological risk factors over the life course of myocardial infarction patients. Adv Cardiol 1982; 29: 132-9.

23. Follick MJ, Gorkin L, Capone RJ, et al. Psychological distress as a predictor of ventricular arrhythmias in a post-myocardial infarction population. Am Heart J 1988; 116: 32-6.

24. Ladwig KW, Kieser M, Konig J, et al. Affective disorders and survival after acute myocardial infarction: results from the post-infarction late potential study. Eur Heart J 1991; 12: 959-64.

25. Stern MJ, Pascale L, Ackerman A. Life adjustment post-myocardial infarction: determining predictive varibles. Arch Intern Med 1977; 137: 1680-5.

26. Dwight MM, Stoudemire A. Effects of depressive disorders on coronary artery disease: A review. Harvard Ver Psychiatry 1997; 5: 115-22.

27. Greenland P, Reicher-Reiss H, Goldbourt U, Behar S. In-hospital and 1-year mortality in 1524 women after myocardial infarction: comparison with 4315 men. Circulation 1991; 83: 484-91.

28. Carney RM, Freedland KE, Smith LJ, Lustman PJ, Jaffe AS. Relation of depression and mortality after myocardial infarction in women. Circulation 1991; 84: 1876-7.

29. Nutt D. Management of patients with depression associated with anxiety symptoms. J Clin Psychiatry 1997; 58: 11-6.

30. Croog SW, Levine S. Life After Heart Attack. New York: Human Sciences Press, 1982: 33p.

31. Carney RM, Freedland KE, Rich MW, Smith LJ, Jaffe AS. Ventricular tachycardia and psychiatric depression in patients with coronary artery disease. Am J Med 1993; 95: 23-8.

32. Musselman DL, Tomer A, Manatunga AK et al. Exagerated platelet reactivity in major depression. Am J Psychiatry 1996; 153: 1313-7.
33. Laghrissi-Thode F, Wagner WR, Pollock BJ, Johnson PC, Finkel MS. Elevated platelet factor 4 and b-thromboglobulin plasma levels in depressed patients with isquemic heart disease. Biol Psychiatry 1997; 42: 290-5.

34. Weyrich AS, Solis GA, Li KS, Tulenko TN, Santamore WP. Platelet amplification of vasoespasm. Am J Physiol 1992; 263: H349-H358.

35. DeClerck F. Effects of serotonin on platelet and blood vessels. J Cardiovasc Pharmacol 1991; 17: S1-S5.

36. BiegonA, Weizman A,KarpL,RamA,IanoS, WolffM.Serotonin5-HT2Receptorbinding on blood platelets: A periferal marker for depression? Life Sci 1987;41: 2485-92.

37. Biegon A, Grinspoon A, Blumenfelt B, Bleish A, Apter A, Mester R. Increased serotonin 5-ht2 receptor binding on blood platelets in suicidal men. Psychopharm 1990; 100: 165-7.

38. Biegon A, Essar N, Israeli M, Elizur A, Bruch S, Bar-Natan AA. Serotonin 5-HT2 receptor binding on blood platelets as a state dependent marker in major affective disorder. Psychopharm 1990; 100: 73-5.

39. Arora RC, Meltzer HY. Increased serotonin (5-HT2) receptor binding as measured by 3H-LSD in the blood platelet of depressive patients. Life Sci 1989; 44: 725-34.

40. Pandey GN, Pandey SC, Janicak PG. Platelet serotonin-2 binding sites in depression and suicide. Biol Psychiatry 1990; 28: 215-22.

41. Nemeroff CB, Knight DL, Franks J, Craighead WF, Krishnan KRR. Further studies on platelet serotonin transporter binding in depression. Am J Psychiatry 1994; 151: 1623-5.

42. Owens MJ, Nemeroff CB. Role of serotonin in the patophysiology of depression: Focus on the serotonin transporter. Clin Chem 1994; 40: 288-95.

43. Briley MS, Langer SZ, Raisman R, SechterD, Zarifian E. Tritiated mipramine binding sites are decreased in platelets of untreated depressed patients. Science 1980; 209: 303-15

44. Langer SZ, Arifian E, Briley MS, Raisman R, Sechter D. High-affinity binding of $3 \mathrm{H}$-imipramine in brain and platelets and its relevance to the biochemistry of affective disorders. Life Sci 1981; 29: 211-8.

45. Paul SM, Rehavi M, Skolnick P, Ballenger JC, Goodwin FK. Depressed patients have decreased binding of titrated imipramine to platelet serotonin transporter. Arch Gen Psychiatry 1981; 38: 1315-7.

46. Nemeroff CB, Knight DL, Krishnan KRR, et al. Marked reduction in the number of platelet $3 \mathrm{H}$-imipramine binding sites in geriatric depression. Arch Gen Psychiatry 1988; 45: 919-23.

47. Lown B, Verrier RL. Neural activity and ventricular fibrillation. N Eng J Med 1976; 294: 1165-70.

48. Schwartz PJ, Snebold NG, Brown AM. Effects of unilateral cardiac sympathetic denervation on the ventricular fibrillation threshold. Am J Cardiol 1976; 37 : 1034-40.

49. Kirby DA, Pinto JMB, Hottinger S, Johnson DA, Lown B. Behavioural arousal enhaces inducibility and rate of ventricular tachycardia. Am J Physiol 1991; 261: H1734-9.

50. Bigger JT Jr, Fleiss JL, Kleiger R, Miller JP, Rolnitzky LM. The relationship among ventricular arrythmias, left ventricular dysfunction, and mortality in 2years after myocardial infarction. Circulation 1984; 69: 250-8.

51. Roose SP, Dalack GW, Woodring S. Death, depression and heart disease. J Clin Psychiatry 1991; 52: 34-9.

52. Kennedy GJ, Hofer MA, Cohen D, Shindledecker MA, Fisher JD. Signifficance of depression and cognitive impairment in patients undergoing programmed stimulation of cardiac arrythmias. Psychosom Med 1987; 49: 410-21.

53. Lake CR, Pickar D, Ziegler MG, Lipper S, Slater S, Murphy DL. High plasma norepinephrine levels in patients with major affective disorder. Am J Psychiatry 1982; 39: 295-300.

54. Roy A, Pickar D, Dejong J, Karoun F, Linnoila M. Norepinephrine ans its metabolites in cerebrospinal fluid, plasma, and urine: relationship to hypothalamic-pituitaryadrenal axis function in depression. Arch Gen Psychiatry 1988; 45: 849-57.

55. Veith RC, Lewis L, Linares AO, et al. Sympathetic nervous system activity in major depression: basal and desipramine-induced alterations in plasma norepinephrine kinetics. Arch Gen Psychiatry 1994; 51: 411-22.

56. Roy A, Pickar D, Linnoila M, Potter WZ. Plasma norepinephrine level in affective disorders: relationship to melancholia. Arch Gen Psychiatry 1985; 42: 1181-5.

57. Malzberg B. Mortality among patients with involution melancholia. Am J Psychiatry 1937; 93: 1231-8.

58. Dalack GW, Roose SP. Perspectives on the relationship between cardiovascular disease and affective disorder. J Clin Psychiatry 1990; 51(suppl 7): 4-9.

59. Rechlin T, Weis M, Aspitzer A, Kaschka H. Are affective disorders associated with alterations of heart rate variability? J Affect Disord 1994; 32: 271-5.

60. Kleiger, RE, Miller JP, Bigger JT, Moss AJ. Decreased heart rate variability and its association with increased mortality after acute myocardial infarction. Am J Cardiol 1987; 59: 256-62.

61. Carney RM, Saunders RD, Freedland KE, et al. Association of depression with reduced heart rate variability in coronary artery disease. Am J Cardiol 1995; 76: 562-4. 
62. Magid NM, Eckberg KL, Sprenkle JM. Low dose atropine reduces ventricular vulnerability in normal and ischemic hearts. J Clin Invest 1983; 31: 261-4.

63. Banki CM, Karmasci L, Bissette G, et al. CSF corticotropin-releasing and somatostatin in major depression: response to antidepressant treatment and relapse. Eur Neuropsycopharmacol 1992; 2: 107-13.

64. Risch SC, Lewine RJ, Kalin NH, et al. Limbic-hypothalamic-pituitary-adrenal axis activity and ventricular-to-brain rature studies in affective illness and schizophrenia. Neuropsycopharmacology 1992; 6: 95-100.

65. Gold PW, Loriaux DL, Roy A, et al. Response to corticotropin-releasing hormone in the hypercorticolism of depression and cushing's disease: pathophysiologic and diagnostic implications. N Engl J Med 1986; 314: 1329-35.

66. Amsterdam JD, Maislin G, Winokur A, et al. Pituitary and adrenocortical response to the ovine corticotropin releasing hormone in depressed patients and healthy volunteers. Arch Gen Psychiatry 1987; 44: 775-81.

67. Charlton BG, Ferrier IN. Hypothalamo-pituitary-adrenal axis abnormalities in depression: a review and a model. Psychol Med 1989; 19: 331-6.

68. Amsterdam JD, Winokur A, Abelman E, et al. Cosyntropin stimulation test in depressed patients and healthy controls. Am J Psychiatry 1983; 140: 907-9.

69. Carrol BJ, Martin FI, Davis BM. Resistance to Supression by Dexamethasone of Plasma 11(OH)CS Levels in Severe Depressive Illness. BMJ 1968; 3: 285-7.

70. Arana GW, Baldessarini RJ, Ornsteen M. The dexamethasone supression test for diagnosis and prognosis in psychiatry: coommentary and review. Arch Gen Psychiatry 1985; 42: 1193-1204.

71. Arana GW, Mossman D. The desamethasone supression test and depression. Endocrinol Metab Clin North Am 1988; 17: 21-39.

72. Roy A, Guthrie S, Pickar D, Linnoila M. Plasma NE responses to cold challenge in depressed patients and normal controls. Psychiatry Res 1987; 21: 161-8.

73. Thompson DR, Meddis R. A Prospective evaluation of in-hospital counselling for first time myocardial infarction men. J Psychosom Res 1990; 34: 237-48.

74. Trzcieniecka-Green A, Steptoe A. Stress management in cardiac patients: a preliminary study of the predictors of improvement in quality of life. J Psychosom Res 1994; 38: 267-80.

75. Linden W, Stossel C, Maurice J. Psychosocial interventions for patients with coronary artery disease: a meta-analysis. Arch Intern Med 1996; 156: 745-52.

76. Glassman AAH, Bigger JT Jr. Cardiovascular effects of therapeutic doses os tricyclic antidepressants: a review. Arch Gen Psychiatry 1981; 38: 815-20.

77. Glassman AH, Roose SP, Giardina EGV. Cardiovascular effects of tricyclic antidepressants. In: Meltzer HY, eds. Psychopharmacology: The Third Generation of Progress. New York: Raven Press, 1987: 1437-42.

78. Roose SP, Glassman AH. Antidepressant Choice in the Patient with Cardiac Disease: Lessons from the Cardiac Arrythmia Supression Trial (CAST) Studies. J Clin Psychiatry 1994; 55: 83-7.

79. Glassman AH, Johnson LL, Giardina EGV et al. The use of imipramine in depressed patients with congestive heart failure. JAMA 1983; 250: 1997-2001.

80. Glassman $\mathrm{AH}$. The newer antidepressant drugs and their cardiovascular effects. Psychopharm Bull 1984; 20: 272-9.

81. Ray WA, Griffin MR, Schaeffner W, et al. Psychotropic drugs usse and the risk of hip fracture. N Engl J Med 1987; 316: 363-9.

82. Glassman AH, Bigger JT Jr, Giardina EGV, et al. Clinical characteristics of imipramine-induced osthostatic hypotension. Lancet 1979; 1: 468-72.
83. Thayssen P, Bjerre M, Kragh-Sprensen P, et al. Cardiovascular effects of imipramine and nortriptyline in elderly. Psychopharmacol 1981; 74: 360-4.

84. Cardiac Arrhytmia Supression Trial (CAST) Investigators. Preliminary reports: effect of encainide and flecainide on mortality in a randomized trial of arrythmia supression after myocardial infarction. N Engl J Med 1989; 321: 406-12.

85. Cardiac Arrhytmia Supression Trial II Investigators (CAST II). Effect of the antiarrhytmic agent moricizine on survival after myocardial infarction. N Engl J Med 1992; 327: 227-33.

86. Sheline YI, Freedland KE, Carney RM. How safe are serotonin reuptake inhi-bitors for depression in patients with coronary heart disease? Am J Med 1997; 102: 54-9.

87. Cooper GL. The safety of fluoxetine: an update. Br J Psychiatry 1988; 153(suppl 3): 77-86.

88. Kuhs H, Rudolf GAE. Cardiovascular effects of paroxetine. Psychopharmacol 1990; 102: 379-82.

89. Crewe HK, Lennard MS, Tucker GT, et al. The effect of selective serotonin reuptake inhibitors on cytochrome P4502D6 (CYP2D6) activity in human liver microsomes. Br J Clin Pharmacol 1992; 34: 262-5.

90. Nemeroff CB, DeVane CL, Pollock BG. Newer antidepressants and the cytochrome P450 system. Am J Psychiatry 1996; 153: 311-20.

91. Golino P, Piscione F, Willerson JT, et al. Divergent effects of serotonin on coronary artery dimensions and blood flow in patients with coronary atherosclerosis and control patients. N Engl J Med 1991; 324: 641-8.

92. McFadden EP, Clarcke JG, Davies GJ, et al. Effect of intracoronary serotonin on coronary vessels in patients with stable angina and patients with variant angina. N Engl J Med 1991; 324: 648-54.

93. Stokes PE. Fluoxetine: a 5-year Review. Clin Ther 1993; 15: 216-43.

94. Dunbar GC, Cohn JB, Fabre LF, et al. AComparison of paroxetine, imipramine and placebo in depressed out-patients. Br J Psychiatry 1991; 159: 394-8.

95. Reimherr FW, Chouinard G, Cohn CK, et al. Antidepressant Efficacy of Sertraline: a Double-bind, Placebo and Amitriptyline-controlled Multicenter Comparison Study in Outpatients with Major Depression. J Clin Psychiatry 1990; 51(suppl B): 18-27.

96. Roose SP, Glassman AH, Attia E, Woodring S. Comparative efficacy of selective serotonin reuptake inhibitors and tricyclics in the treatment of melancholia. Am J Psychiatry 1994; 151: 1735-9.

97. Roose SP, Laghrissi-Thode F, Kennedy JS, et al. Comparison of paroxetine and nortriptyline in depressed patients with ischemic heart disease. JAMA 1998; 279: 287-91.

98. Roose SP, Dalack GW, Glassman AH, et al. Cardiovascular effects of bupropion in depressed patients with heart disease. Am J Psychiatry 1991; 148: 512-6.

99. Khan A, Fabre LF, Rudolph R. Venlafaxine in depressed outpatients. Psychopharmacol Bull 1991; 27: 141-4.

100. Anon. Venlafaxine: a new dimension in antidepressant pharmacotherapy. J Clin Psychiatry 1993; 54: 119-26.

101. Smith WT, Glaudin V, Panagides J, et al. Mirtazapine vs amitriptyline vs placebo in the treatment of major depression disorder. Psychopharmacol Bull 1990; 26: 191-6.

102. Vitullo RN, Wharton JM, Allen NB, Pritchet EL. Trazodone-related exercise-induced nonsustained ventricular tachycardia. CHEST 1990; 98: 247-8.

103. Hyman SE, Arana GW, Rosenbaueu JF. Handbook of psychiatry drug therapy. 3 ed. Boston: Little, Brown and Company 1995; pp81.

104. Lasnier C, Marey C, Lapeyreg G, Delalleau B, Ganry H. 4 Cardiovascular acceptability of tianeptine. Presse Med 1991; 20: 1858-63.

105. Avery D, Winokur G. Mortality in depressed patients treated with electroconvulsive therapy and antidepressants. Arch Gen Psychiatry 1976; 33: 1029-37. 